\title{
Influência de agentes clareadores nas propriedades superficiais (rugosidade e microdureza) de uma cerâmica odontológica
}

\section{(Influence of bleaching agents on the surface properties (roughness and microhardness) of a dental ceramic)}

\author{
H. de A. Ferreira, H. L. Carlo, F. D. C. M. e Silva, S. S. Meireles, R. M. Duarte, A. K. M. de Andrade \\ Universidade Federal da Paraíba, UFPB, João Pessoa, PB, Brasil \\ heloisaaf19@gmail.com,hugo@ccs.ufpb.br,fabiadanielle2@yahoo.com.br,soniasaerge@hotmail.com,rose_ \\ marquesd@hotmail.com,kamandrade@hotmail.com
}

\begin{abstract}
Resumo
O objetivo desse estudo in vitro foi avaliar a influência de agentes clareadores na rugosidade superficial e na microdureza de uma cerâmica odontológica (porcelana). Foram confeccionadas 30 amostras de cerâmica odontológica de $2 \mathrm{~mm}$ de espessura e $6 \mathrm{~mm}$ de diâmetro de acordo com as instruções do fabricante. Posteriormente, as amostras foram aleatoriamente divididas em 3 grupos $(\mathrm{n}=10)$ e avaliadas quanto à rugosidade e à microdureza para obtenção dos valores iniciais. Dois grupos foram submetidos ao tratamento superficial com agentes clareadores (GII: peróxido de hidrogênio a 9,5\% e GIII: peróxido de hidrogênio a 37,5\%). O GI, que constituiu o grupo controle, ficou imerso em água destilada. O peróxido de hidrogênio a 9,5\% foi aplicado 3 h/dia por 3 semanas. O agente mais concentrado foi utilizado 3 vezes ao dia, por 8 min durante 3 semanas (uma vez por semana). Ao fim de cada exposição ao agente clareador, os espécimes foram lavados e armazenados em água destilada. Os dados obtidos relativos à rugosidade e à microdureza dos espécimes cerâmicos foram registrados nos intervalos de tempo: inicial (baseline) e 3 semanas após a aplicação dos agentes clareadores. A rugosidade e a microdureza de superfície não foram alteradas de maneira estatisticamente significativa, considerando o tempo de clareamento, independente do grupo analisado $(\mathrm{p}>0,05)$. Os valores médios da rugosidade (Ra em $\mu \mathrm{m}$ ) foram: GI $(0,084,0,086,0,078,0,083)$, GII $(0,085,0,085,0,086,0,080)$ e GIII $(0,079,0,088,0,083,0,086)$. Os valores médios de microdureza $\left(\mathrm{VHN}\right.$ em $\left.\mathrm{kgf} / \mathrm{mm}^{2}\right)$ foram: GI $(618,589)$, GII $(573,578)$ e GIII $(584,600)$. Concluiu-se que as propriedades superficiais (rugosidade e microdureza) da cerâmica odontológica não foram alteradas pelo tratamento clareador. Novas pesquisas são necessárias para explicar o efeito do clareamento em cerâmicas odontológicas.
\end{abstract}

Palavras-chave: cerâmica, clareamento dental, clareadores.

Abstract

The objective of this in vitro study was to evaluate the effect of bleaching agents on the surface roughness and microhardness of a dental ceramic (porcelain). Thirty samples of dental ceramic, $2 \mathrm{~mm}$ thick and $6 \mathrm{~mm}$ in diameter, were prepared according to manufacturer's instructions, randomly divided into three groups of 10, and their initial baseline roughness and microhardness values recorded. Two groups were submitted to surface treatment with bleaching agents (GII, hydrogen peroxide 9.5\%; and GIII, hydrogen peroxide $37.5 \%)$. The third group, GI, remained immersed in distilled water constituting the control group. GII group was exposed to the bleaching agent three hours a day for three weeks. As for the GIII group, the bleaching agent was applied three times a day, for eight minutes, during three weeks (once a week). After each exposure to the bleaching agent, the samples were washed and stored in distilled water. The roughness and microhardness data for the different ceramic specimens were collected at time intervals: initial (baseline) and every 3 weeks after bleaching agent applications. None of the bleaching treatments applied altered the roughness or the micro-hardness of the ceramic surfaces in any statistically significant way ( $p>0.05)$. Average roughness (Ra in $\mu \mathrm{m})$ values registered were: for GI (0.084, 0.086, 0.078, 0,083); for GII (0.085, 0.085, 0.086, 0.080); and for GIII (0.079, 0.088, $0.083,0.086)$. Average microhardness (VHN in $\left.\mathrm{kgf} / \mathrm{mm}^{2}\right)$ values registered were: for GI $(618,589)$; for GII $(573$, 578); and for GIII $(584,600)$. It is concluded that the dental ceramic' surface properties (roughness and microhardness) were not altered by the bleaching treatments applied. Additional studies are necessary to understand and explain the effect of bleaching on dental ceramics. Keywords: ceramics, dental bleaching, bleaching.

\section{INTRODUÇÃO}

A estética do sorriso de uma pessoa é influenciada em grande parte pela coloração, forma, posição e má formação dentária, muitas vezes prejudicando as suas relações sociais [1]. Com isso, a quantidade de pacientes que procuram a estética ideal está crescendo cada vez mais [2]. Dentes com coloração mais escura que o normal podem ser tratados utilizando-se diversas técnicas restauradoras, como restaurações de resinas compostas diretas, coroas ou facetas de cerâmica ou até mesmo o clareamento dentário $[3,4]$. Geralmente, a cor do dente pode ser melhorada por 
abordagens incluindo dentifrícios clareadores, limpeza profissional e polimento para remover manchas e cálculo dentário e microabrasão do esmalte com abrasivos e ácidos. Como uma técnica conservadora para clarear os dentes naturais e para remover as manchas, o clareamento dentário tornou-se um procedimento popular em dentística, por ser um tratamento restaurador eficiente e não invasivo, passando a ser frequentemente solicitado pelos pacientes que desejam melhorar a coloração de seus dentes [5, 6]. Muitos sistemas estão disponíveis, mas aqueles com eficácia comprovada compartilham o mecanismo comum de peróxido. A forma do peróxido (de hidrogênio e de carbamida) e os métodos de aplicação variam, mas todos mostram eficácia. Há uma grande base de pesquisa de apoio à utilização destes materiais, mas pouco também tem sido realizado sobre os seus possíveis efeitos deletérios no interior da cavidade oral, utilizando adequados modelos in situ ou in vivo [7].

As técnicas de clareamento podem ser classificadas por elas envolverem dentes vitais ou não vitais e se o procedimento é realizado em consultório odontológico ou em casa. $\mathrm{O}$ uso de clareamento para melhorar a estética da dentição natural aumentou apenas após a introdução do sistema de clareamento caseiro na década de 1990. Essa técnica apresenta relativa facilidade de aplicação, menor custo, disponibilidade geral para todas as classes socioeconômicas, segurança dos materiais utilizados e elevada percentagem de tratamentos bem sucedidos [3, 4]. A duração do tratamento com o clareamento caseiro pode variar amplamente e depende do tempo de aplicação que o paciente utiliza por dia [8]. Com o tempo, os sistemas de clareamento de dentes em consultório empregando o uso de oxidantes fortes foram reintroduzidos. As vantagens são: o tratamento é totalmente sob o controle do dentista, os tecidos moles são geralmente protegidos do processo e o potencial para o clareamento é mais rápido $[3,4]$. Os agentes clareadores modernos mais usados para descoloração do dente são o peróxido de hidrogênio ou o peróxido de carbamida, penetrando nos tecidos duros dentais e são capazes de oxigenar as substâncias corantes (cromóforos) adsorvidas ou absorvidas pelos tecidos dentários. No processo de clareamento, o peróxido ataca as ligações duplas insaturadas dos cromóforos, que resulta em moléculas e partículas oxigenadas incolores. Os cromóforos perdem sua capacidade de coloração e a cor natural do dente é restaurada [7]. Muitos dos sistemas disponíveis hoje usam o peróxido de carbamida de 10, 15, 20 ou 35\% como agente ativo. As soluções de peróxido de carbamida são muito instáveis e imediatamente se dissociam em seus constituintes após aplicação clínica, ao entrar em contato com o tecido ou a saliva. Sua reação com os dentes libera peróxido de hidrogênio e radicais livres, que são responsáveis pelo clareamento dental; apesar da ampla aprovação das técnicas de clareamento dental, o uso de peróxidos pode causar efeitos adversos, devido à natureza reativa do peróxido de hidrogênio, tais como sensibilidade dentinária e irritação gengival. Várias alterações microscópicas na morfologia da superfície do esmalte são também observadas, como perda de mineral do esmalte e superfície rugosa. Os radicais livres, lançados pelos agentes clareadores, são extremamente reativos e instáveis, e o baixo pH são descritos como as principais causas dos efeitos colaterais do uso destes produtos $[9,10]$. Muitos estudos têm demonstrado que este tratamento é eficaz no clareamento de certos tipos de dentes escurecidos, mas seu efeito sobre os materiais restauradores não é claramente compreendido $[2,6,11]$.

Uma revisão recentemente publicada mostrou que o clareamento dental é relativamente seguro em termos de risco potencial para o tecido duro dental. Os possíveis efeitos sobre os tecidos duros dentais são discutidos como sendo mínimo e não é relevante, desde que os agentes clareadores sejam aplicados segundo as instruções do fabricante. Ao lado disto, alguns autores expressam preocupação sobre o efeito desses agentes em materiais restauradores odontológicos, sobre suas propriedades físicas, superfície, forma e cor [12, 13]. O uso por muito tempo de agentes clareadores pode causar mudanças estruturais nos materiais restauradores e comprometer suas propriedades físicas e levar à falha prematura [10]. Restaurações de cerâmica estão sendo cada vez mais utilizadas pela população, por apresentar propriedades estéticas, físicas e mecânicas desejáveis [2]. Embora a cerâmica dental convencional seja considerada o material restaurador mais inerte entre todos os outros, suas superfícies podem apresentar deterioração superficial em contato com o gel de flúor acidulado ou outras soluções. Além disso, o contato e a possível difusão de radicais livres produzidos por agentes clareadores seletivamente podem lixiviar íons alcalinos e causar dissolução no vidro cerâmico. Assim, a exposição prolongada ao peróxido de hidrogênio através do tratamento de clareamento dental pode potencialmente afetar a cerâmica dentária e pode produzir alterações na sua superfície, como o aumento da rugosidade superficial. Pode também resultar em um aumento no acúmulo de biofilme, aumentando assim o risco de cáries secundárias e inflamação periodontal, o que afeta a cerâmica estética e altera sua textura [10]. Uma vez que o aumento da rugosidade na superfície da cerâmica poderia levar a mais retenção de biofilme, aderência bacteriana e irritação gengival, os autores sugeriram proteger esses materiais com uma barreira antes do clareamento para preservar a integridade da superfície cerâmica [14]. Alguns autores relataram que as técnicas de clareamento não têm nenhum efeito significativo sobre a cor ou as propriedades físicas de materiais cerâmicos, bem como amálgama ou ouro [7]. Outros estudos mostraram que agentes clareadores podem afetar adversamente a rugosidade de superfície de certas cerâmicas dentárias; essas mudanças podem ser causadas ao longo da superfície da cerâmica por uma redução de moléculas de dióxido de silício $\left(\mathrm{SiO}_{2}\right)$ e peróxido de potássio $\left(\mathrm{K}_{2} \mathrm{O}_{2}\right)$, mas tais mudanças são altamente dependentes do material e da duração de exposição, ou seja, diferenças significativas podem ser detectadas apenas após 8 semanas de uso do produto [14]. Zaki e Fahmy (2009) mostraram que o clareamento não teve um impacto clinicamente significativo sobre uma série de materiais restauradores. 
Os efeitos dos agentes clareadores sobre a microdureza dos materiais restauradores permanecem controversos [5]. Em virtude da variedade de marcas comerciais de agentes clareadores disponíveis no mercado, torna-se necessário pesquisar o efeito de agentes clareadores nas propriedades da cerâmica odontológica. Assim, o cirurgião-dentista ficará atento quanto aos efeitos da exposição direta das restaurações cerâmicas aos sistemas clareadores e quanto aos cuidados para promover uma maior longevidade clínica das restaurações. O objetivo desse estudo in vitro foi avaliar a influência de agentes clareadores na rugosidade superficial e na microdureza de uma cerâmica odontológica, após aplicação de diferentes agentes clareadores (peróxido de hidrogênio a $9,5 \%$ e a $37,5 \%$ ).

\section{MATERIAIS E MÉTODOS}

Foi realizado um estudo laboratorial, no qual foi adotada uma abordagem indutiva, com procedimento estatístico e comparativo, com técnica de documentação direta em laboratório. Para confecção dos corpos de prova (amostras) foi utilizada uma cerâmica odontológica, a saber: cerâmica de esmalte (Noritake EX-3 Dental Supply Co, Aichi, Japan) na cor E1. Trinta espécimes cerâmicos, de $2 \mathrm{~mm}$ de espessura e $6 \mathrm{~mm}$ de diâmetro, foram individualmente preparados num molde metálico. As amostras resultantes foram sinterizadas em um forno cerâmico (Alumini 50, EDG, S. Carlos, SP, Brasil). Após esta preparação, os trinta espécimes foram submetidos ao glazeamento, de acordo com as instruções do fabricante, e ao polimento com lixas de carbeto de silício de grau 800 e 1200 e disco de feltro (FGM, Joinville, SC, Brasil) com pasta diamantada (FGM, Joinville, SC, Brasil). Após o tratamento superficial, os espécimes foram armazenados em água destilada por $24 \mathrm{~h}$.

Análise da rugosidade superficial inicial: o ensaio foi realizado, após o período de armazenagem de $24 \mathrm{~h}$, em rugosímetro (Surftest SJ-301, Mitutoyo, Japão). Os corpos de prova foram individualmente adaptados sobre uma placa de vidro com cera utilidade, com o auxílio de uma prensa, com carga de 0,5 kgf durante $3 \mathrm{~s}$. Foram então levados ao rugosímetro, com as seguintes condições de teste: comprimento de amostragem Lc (cut-off/filtragem, que minimiza a interferência de ondulação da superfície) de $0,25 \mathrm{~mm}$ e velocidade de $0,5 \mathrm{~mm} / \mathrm{s}$. Três leituras aleatórias por espécime foram realizadas, rotacionando o corpo de prova, e os valores médios foram calculados. Para a leitura da rugosidade superficial, houve ajuste do equipamento com parâmetro $\mathrm{Ra}(\mu \mathrm{m})$ que traduz o valor da média aritmética de todas as distâncias absolutas do perfil de rugosidade desde a linha central, dentro da extensão de medida Lm (limite de medição).

Análise da microdureza inicial: o ensaio foi realizado, após o período de armazenagem de $24 \mathrm{~h}$, em um microdurômetro digital HMV-G20 (Shimadzu Corporation, Kyoto, Japão). Os corpos de prova foram individualmente adaptados sobre uma placa de vidro com adesivo dupla face. Foram então levados ao microdurômetro, com as seguintes condições de teste: força de $100 \mathrm{gf}$ aplicadas através de indentação Vickers durante 15 s. Cinco leituras, na superfície de cada corpo de prova, foram realizadas e a média registrada.

Divisão dos grupos: as amostras foram divididas em 3 grupos $(n=10)$ de acordo com o agente clareador: (1) G I água destilada (controle); (2) G II - peróxido de hidrogênio a 9,5\% / Pola Day (SDI Brasil, Pinheiros, S. Paulo, SP); (3) G III - peróxido de hidrogênio a 37,5\% / Pola Office+ (SDI Brasil, Pinheiros, S. Paulo, SP). O grupo controle foi mantido em água destilada durante 3 semanas. O grupo que utilizou peróxido de hidrogênio $9,5 \%$ foi exposto $3 \mathrm{~h} /$ dia por 3 semanas, de acordo com as recomendações do fabricante. $\mathrm{O}$ agente Pola Office+ (SDI) foi aplicado 3 vezes no mesmo dia, por 8 min durante 3 semanas (uma vez por semana), segundo as instruções do fabricante. Ao fim de cada exposição ao agente clareador, os espécimes foram lavados e armazenados em água destilada.

Avaliação da rugosidade e da microdureza ao longo do tempo: os dados obtidos relativos à rugosidade dos espécimes cerâmicos foram registrados nos seguintes intervalos de tempo: inicial (baseline), 1, 2 e 3 semanas após a aplicação dos agentes clareadores; e os dados obtidos relativos à microdureza dos espécimes cerâmicos foram registrados nos intervalos de tempo: inicial (baseline) e 3 semanas após a aplicação dos agentes clareadores. As aferições das propriedades das amostras foram efetuadas da mesma maneira supradescrita para a avaliação inicial.

Análise dos dados: os valores da rugosidade superficial e da microdureza obtidos foram analisados estatisticamente, através do teste de Friedman, do teste de Wilcoxon e do teste de Kruskal Wallis $(\mathrm{p}<0,05)$.

\section{RESULTADOS}

A rugosidade de superfície (Tabela I) não foi alterada de maneira estatisticamente significativa, considerando o tempo

Tabela I - Média e desvio-padrão da rugosidade superficial (Ra em $\mu \mathrm{m}$ ) após tratamento clareador. [Table I - Mean and standard deviation for surface roughness measurements (Ra in $\mu \mathrm{m})$.]

\begin{tabular}{ccccc}
\hline Grupo & Baseline & Após 1 semana & Após 2 semanas & Após 3 semanas \\
\hline Água destilada & $0,084( \pm 0,008)$ & $0,086( \pm 0,011)$ & $0,078( \pm 0,015)$ & $0,083( \pm 0,007)$ \\
Peróxido de hidrogênio a $9,5 \%$ & $0,085( \pm 0,011)$ & $0,085( \pm 0,011)$ & $0,086( \pm 0,012)$ & $0,080( \pm 0,014)$ \\
Peróxido de hidrogênio a 37,5\% & $0,079( \pm 0,007)$ & $0,088( \pm 0,014)$ & $0,083( \pm 0,015)$ & $0,086( \pm 0,008)$ \\
\hline
\end{tabular}


de clareamento, independente do grupo analisado ( $\mathrm{p}>0,05)$. As rugosidades foram comparadas em cada grupo (teste de Friedman) e em cada tempo (teste de Kruskal Wallis).

A microdureza de superfície (Tabela II) também não foi alterada de maneira estatisticamente significativa, considerando o tempo de clareamento, independente do grupo analisado $(p>0,05)$. Os valores de microdureza foram comparados em cada grupo (teste de Wilcoxon) e em cada tempo (teste de Kruskal Wallis).

Tabela II - Média e desvio-padrão da microdureza superficial (VHN em $\mathrm{kgf} / \mathrm{mm}^{2}$ ) após tratamento clareador.

[Table II - Mean and standard deviation for microhardness measurements (VHN in $\mathrm{kgf} / \mathrm{mm}^{2}$ ).]

\begin{tabular}{ccc}
\hline Grupo & Baseline & $\begin{array}{c}\text { Após 3 } \\
\text { semanas }\end{array}$ \\
\hline Água destilada & $618( \pm 27)$ & $589( \pm 28)$ \\
Peróxido de hidrogênio a 9,5\% & $573( \pm 56)$ & $578( \pm 25)$ \\
Peróxido de hidrogênio a 37,5\% & $584( \pm 34)$ & $600( \pm 29)$ \\
\hline
\end{tabular}

\section{DISCUSSÃO}

Espera-se que a cerâmica, enquanto material restaurador de uso odontológico, seja quimicamente estável na boca, uma vez que ficará exposta a degradação por diversas soluções com $\mathrm{pH}$ variável, por desgaste, por abrasão e por forças realizadas pelas estruturas dentárias opostas. Essa exposição pode estimular a liberação de substâncias pela cerâmica, podendo aumentar a adesão de biofilme após tais desafios intraorais [10]. A degradação da cerâmica odontológica geralmente ocorre por causa de ataques químicos, forças mecânicas ou uma combinação destes efeitos. Neste estudo foram feitos ataques químicos diários (peróxido de hidrogênio 9,5\%) e semanais (peróxido de hidrogênio $37,5 \%)$, mas diferentes resultados podem ser encontrados se forças mecânicas forem aplicadas, porque elas podem enfraquecer a estrutura, criando rachaduras superficiais. $\mathrm{O}$ protocolo clareador utilizado neste estudo foi semelhante ao utilizado em outros estudos $[8,10,15]$, que visava avaliar in vitro o efeito do sistema de clareamento na rugosidade e na microdureza da superfície da cerâmica odontológica. Este estudo testou os efeitos de agentes usados em clareamento dental sobre a rugosidade e a microdureza da superfície das amostras de cerâmicas com médias de rugosidade inicial padronizada com menos de $0,2 \mu \mathrm{m}$ (condição que leva ao acúmulo bacteriano) [10]. Foi observado que não houve diferença significativa na rugosidade e na microdureza da cerâmica em nenhuma das análises (7, 14 e 21 dias) de exposição ao peróxido de hidrogênio a $9,5 \%$ e a $37,5 \% \mathrm{em}$ comparação com os valores da linha base. Entretanto, esses resultados encontram-se muito divergentes na literatura.

Os resultados deste trabalho se assemelham a diversos estudos encontrados com relação à rugosidade. Em outro estudo não foram encontradas diferenças estatísticas significativas nos valores de Ra nas superfícies da cerâmica tratadas com peróxido de carbamida a $10 \%$ e a $15 \%$ [16] $\mathrm{Na}$ pesquisa em que examinaram os efeitos de agentes clareadores com peróxido de carbamida na superfície da cerâmica feldspática, não foram encontradas diferenças significativas na rugosidade de superfície [15]. Essa pesquisa corrobora ainda com o trabalho que avaliou in vitro o efeito de diferentes concentrações de peróxido de carbamida (10\% e 16\%) sobre cerâmicas odontológicas e não foi observada diferença significativa na rugosidade de superfície independente dos intervalos de clareamento [10]. No entanto, outros autores têm demonstrado que géis clareadores afetaram a aspereza da superfície da cerâmica odontológica. Há um estudo que demonstrou um aumento estatisticamente significativo na rugosidade da superfície do material cerâmico após 21 dias de aplicação diária com peróxido de carbamida a $10 \%$ e uma aplicação semanal de gel a 35\%. No entanto, segundo os autores, todos os valores de Ra estavam em um intervalo de 0,22 a 0,24 $\mu \mathrm{m}$, que são clinicamente aceitáveis e as alterações clínicas apresentam-se insignificantes [8]. Da mesma forma, uma pesquisa comparou a rugosidade superficial de três cerâmicas diferentes após exposição a fluoreto e peróxido de carbamida a $10 \%$ e foi encontrada alteração na rugosidade estatisticamente significativa após o uso de cada solução [17].

Com relação a resultados sobre dureza, a literatura também aponta divergências. Existem estudos com resultados semelhantes aos presentes. Em um, avaliaram os efeitos de agentes clareadores a base de peróxido de hidrogênio e peróxido de carbamida sobre o amálgama, o ouro dental, a cerâmica, o ionômero de vidro e compósitos, e concluíram que o tratamento clareador não produziu alterações na morfologia da superfície, nem na microdureza dos materiais [18]. Os resultados deste trabalho também estão de acordo com o trabalho que avaliou in vitro o efeito do clareamento de consultório, peróxido de hidrogênio a $38 \%$, na microdureza de materiais restauradores, entre eles a cerâmica orgânica modificada (Ormocer) e uma cerâmica feldspática. Não foram encontradas diferenças estatisticamente significativas após uso do gel clareador. Em um estudo posterior, os mesmos autores avaliaram o efeito in vitro de um agente clareador caseiro na microdureza dos materiais restauradores supracitados. A análise estatística também mostrou que a técnica do clareamento não teve efeito significativo sobre a microdureza [3]. Ainda concordando com os resultados desse estudo, examinaram os efeitos do peróxido de carbamida a $10 \%$ na dureza de superfície de quatro resinas compostas, um compômero, um cimento de ionômero de vidro e uma cerâmica. Apenas a cerâmica não apresentou diferença estatística após o uso do agente clareador [19]. Em um estudo posterior, avaliaram os efeitos da temperatura e do gel clareador composto por peróxido de hidrogênio a $40 \%$ nas propriedades de superfície de diversos materiais restauradores estéticos, inclusive de um material cerâmico. A análise da microdureza não apresentou diferenças estatísticas para os resultados da cerâmica analisada [5]. Entretanto, alguns estudos na literatura discordam desses resultados. Pesquisadores investigaram os 
efeitos de três agentes clareadores caseiros (dois peróxidos de carbamida a $10 \%$ e outro a $16 \%$ ) na microdureza de uma cerâmica feldspática, de uma resina composta e de um cimento de ionômero de vidro. Encontraram diferenças estatisticamente significativas para a análise da microdureza na cerâmica feldspática e na resina composta [20]. Outra pesquisa avaliou o efeito do agente clareador caseiro com peróxido de carbamida a $20 \%$ e com peróxido de hidrogênio a $10 \%$ sobre a microdureza de dois compósitos e três cerâmicas. Após análise da microdureza, observouse que o agente clareador contendo peróxido de carbamida influenciou significativamente a dureza de todos os materiais restauradores avaliados [1]. Por essa razão, mais estudos são necessários para avaliar esse desafio clínico. Neste sentido, o presente estudo mostrou que a cerâmica odontológica não foi afetada pelos agentes clareadores. Então, a substituição de restaurações de cerâmica em determinadas situações clínicas em que elas são acidentalmente expostas a géis clareadores não é necessária, desde que sua estética, forma e função estejam clinicamente aceitáveis, mas não deixa de ser necessária a proteção dessas restaurações com uma barreira antes do clareamento para preservar a integridade da superfície da cerâmica [14].

\section{CONCLUSÕES}

Concluiu-se que: a rugosidade e a microdureza da superfície da cerâmica odontológica não apresentaram alterações pelos agentes clareadores (peróxido de hidrogênio a $9,5 \%$ e a $37,5 \%$ ) após 21 dias de tratamento; o material cerâmico permaneceu estável nas condições avaliadas.

\section{REFERÊNCIAS}

[1] Ö. Malkondu, H. Yurdagüven, E.C. Say, E. Kazazoğlu, M. Soyman, Oper. Dent. 36, 2 (2011) 177-186.

[2] H.B. Kara, F. Aykent, B. Ozturk, Oper. Dent. 38, 1 (2013) E1-8.

[3] O. Polydorou, E. Hellwig, T.M. Auschill, J. Am. Dent.
Assoc. 138, 7 (2007) 978-984.

[4] O. Polydorou, J.S. Mönting, E. Hellwig, T.M. Auschill, Dent. Mater. 23, 2 (2007) 153-158.

[5] H. Yu, Q. Li, Y.N. Wang, H. Chang, J. Dent. 41, 12 (2013) 1290-1296.

[6] F. Yalcin, S. Gürgan, Dent. Mater. 21, 5 (2005) 464-468. [7] A.A. Zaki, N.Z. Fahmy, J. Prosthodont. 18, 3 (2009) 223229.

[8] R.R. Moraes, J.L. Marimon, L.F. Schneider, L. Correr Sobrinho, G.B. Camacho, M. Bueno, Clin. Oral Investig. 10, 1 (2006) 23-28.

[9] N. Akal, H. Over, A. Olmez, H. Bodur, J. Clin. Pediatr. Dent. 25, 4 (2001) 293-296.

[10] S.A. Ourique, C.A. Arrais, A. Cassoni, C. Ota-Tsuzuki, J.A. Rodrigues, Braz. Oral Res. 25, 5 (2011) 453-458.

[11] M.F. de A. Silva, R.M. Davies, B. Stewart, W. Devizio, J. Tonholo, J.G. Silva Jr., I. A. Pretty, Dent. Mater. 22, 10 (2006) 919-924.

[12] T. Attin, P.R. Schmidlin, F. Wegehaupt, A. Wiegand, Dent. Mater. 25, 2 (2009) 143-157.

[13] T. Attin, C. Hannig, A. Wiegand, R. Attin, Dent. Mater. 20, 9 (2004) 852-861.

[14] J. El-Murr, D. Ruel, A. J. ST-Georges, J. Can. Dent. Assoc. 77 (2011) 1-6.

[15] S.B. Turker, T. Biskin, J. Prosthet. Dent. 89, 5 (2003) 466-473.

[16] A.C. Zavanelli, V.Q. Makarro, C.R. Silva, R.A. Zavanelli, D.N. Mancuso, Int. J. Prosthodont. 24, 2 (2011) 155-157.

[17] C.J. Butler, R. Masri, C.F. Driscoll, G.A. Thompson, D.A. Runyan, J.A. von Fraunhofer, J. Prosthet. Dent. 92 (2004) 179-183.

[18] H. Duschner, H. Götz, D.J. White, K.M. Kozak, J.R. Zoladz, J. Clin. Dent. 15, 4 (2004) 105-111.

[19] H. Yu, Q. Li, H. Cheng, Y. Wang, J. Prosthet. Dent. 105, 2 (2011) 100-107.

[20] S.B. Turker, T. Biskin, J. Oral Rehabil. 29 (2002) $657-$ 666.

(Rec. 11/09/2015, Rev. 07/10/2015, Ac. 22/10/2015) 